\title{
Hyaluronic acid/ Hyaluronidase as biomarkers for bladder cancer: a diagnostic meta-analysis
}

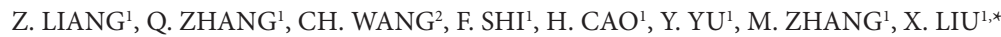 \\ ${ }^{1}$ Epidemiology and Statistics, School of Public Health, Jilin University, Changchun, Jilin, China; ${ }^{2}$ School of Mathematics and Statistics, Northeast \\ Normal University, Changchun, Jilin, China
}

*Correspondence: liuxin2015722010@163.com

Received September 18, 2016 / Accepted November 10, 2016

\begin{abstract}
This study aimed to determine the value of HA/HAase for detecting bladder cancer on the basis of preceding statistical performance. PubMed, Springer Link, Web of Science and Cochrane Library were systematically searched to identify potentially relevant published articles by using the key words: "bladder cancer or bladder tumor or bladder carcinoma" "hyaluronic acid or hyaluronan", "hyaluronidase or HAase". The methodological quality of each study was assessed by QUADAS-2. According to the inclusive and exclusive criteria, 8 articles were identified and methodologically analyzed by STATA 12.0 software package. The results showed that the pooled sensitivity of HA and HAase was 0.832 (95\% confidence interval [CI]: 0.798, 0.861) and 0.834 (95\% CI: 0.756, 0.891) respectively, the pooled specificity was 0.886 (95\% CI: $0.852,0.913)$ and 0.860 (95\% CI: 0.801 , 0.904), and the area under the summary ROC cure (AUC) was 0.90 (95\% CI: 0.87, 0.92) and 0.91 (95\% CI: 0.88, 0.93), respectively. Simultaneously the diagnostic accuracy of the combination of HA and HAase showed that the pooled sensitivity was 0.908 (95\% CI: 0.879, 0.931), the pooled specificity was 0.825 (95\% CI: 0.789, 0.856) and AUC was 0.94 (95\% CI: 0.91 , 0.95), indicating a relatively higher accuracy than HA and HAase alone. This meta-analysis strongly suggests that HA/HAase could be used as biomarkers for the diagnosis of bladder cancer.
\end{abstract}

Key words: bladder cancer, hyaluronic acid, hyaluronidase, diagnosis, meta-analysis

Bladder cancer (BC), the most common carcinoma in urinary system [1], is the twelfth most frequently diagnosed cancer all over the world, and the sixth in developed country and sixteenth in developing country [2]. The majority of bladder cancers occur in males and there is nearly a 14 -fold variety in incidence among different countries [3]. In general, only when a patient presents with hematuria, bladder cancer could be then detected [4]. Cytology and cystoscopy are the principle methods for the diagnosis of patients with bladder cancers [5]. However, these two kinds of approaches have low sensitivity and specificity, consequently, early diagnosis of bladder cancer remains a challenge [6]. Meanwhile, despite significant advances in the molecular pathology of bladder cancer, it is still a significant health problem [7]. Given the importance of early diagnosis for bladder cancer, new biomarkers to reduce the frequency of $\mathrm{BC}$ are conceivable [8]. Hyaluronidase (HAase) is a kind of glycosidase which mainly degrade hyaluronic acid (HA) [9], and HA is a glycosaminoglycan that has osmotic, homeostatic, and structural properties in normal tissues [10]. Both HA and HAase are known to play important roles during embryonic development, vascular remodeling, immune surveillance, and tumor progression [11, 12]. Studies reported that HA regulates cell adhesion $[13,14]$, has an influence on cell proliferation and migration $[15,16]$, and the accumulation of HA in tumour interstitial fluid correlates with lymph node metastasis [17]. Lokeshwar VB' study showed that HAase was involved in tumor growth and tumor angiogenesis $[18,19]$. Previous studies also reported that HA and HAase were both associated with several different kinds of carcinomas [20]. And the association between HA/HAase and bladder cancer has also been studied for a few years, but so far, there was no meta-analysis on the diagnostic value of $\mathrm{HA} / \mathrm{HAase}$ as biomarkers for bladder cancer detection. What's more, the individual studies showed different diagnostic accuracy, for example, Lokeshwar and colleagues reported that urinary HA measurement has a sensitivity and specificity of 91.9\% and $92.8 \%$ to detect bladder cancer, respectively [21], but in a cross-sectional study of 194 urine specimens (97 
bladder cancer patients and 97 control individuals), the HA test showed a sensitivity of $82.5 \%$ and a specificity of $89.7 \%$, in addition, the HA-HAase test showed $89.7 \%$ sensitivity and 83.5\% specificity for bladder cancer [22]. Measurement of the levels of HA/HAase seems to be a highly accurate method for detecting bladder cancer. In this study, we are aiming to summarize the experimental studies to confirm the potential value of HA/HAase as BC marker. To our knowledge, this is the first meta-analysis for the assessment of the roles of HA/ HAase in the diagnosis of bladder cancer.

\section{Materials and methods}

Search strategy, selection criteria. To identify all primary research literatures in which the value of hyaluronidase in BC were analyzed, electronic databases, including PubMed, Springer Link, Web of Science and Cochrane Library were used by searching key words: "bladder cancer or bladder tumor or bladder carcinoma", "hyaluronic acid or hyaluronan or HA", "hyaluronidase or HAase". We only collected data from papers published in English, ruling out meeting or conference abstracts.

The included studies meet the following criteria: (1) original study; (2) HA/HAase serves as biomarkers for BC diagnosis; (3) the diagnosis of bladder cancer was based on cytology and cystoscopy; (4) sufficient information to build $2 \times 2$ tables for calculating sensitivity and specificity; (5) when multiple publications reported on the same or overlapping data, we used the most recent or largest population; (6) the publication language was confined to English.

The exclusive criteria are as follows: (1) studies from conference abstracts, letters, editorials or reviews; (2) studies without control groups; (3) studies without valid data (sensitivity, specificity, true positive, false positive, false negative and true negative).

Data extraction. Data were extracted from each study by two reviewers independently using pre-specified selection criteria. Decisions were made and discordances about study

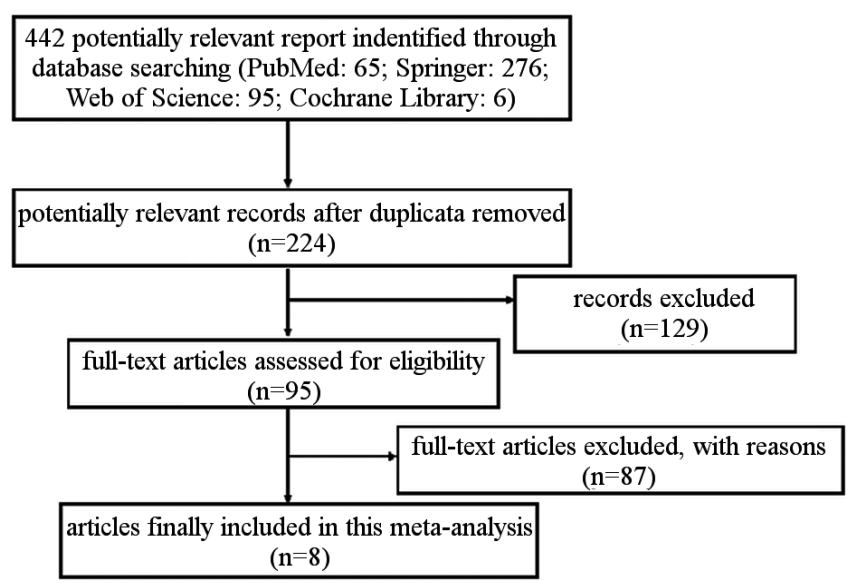

Figure 1. Flow diagram for selection of studies for the meta-analysis. selection were resolved by consensus or by involving a third assessor. The following information was extracted from the studies: first author, publication data, sample size, test method, true positive (TP), false positive (FP), false negative (FN) and true negative (TN).

Quality assessment. We carried out quality assessment by using the Quality Assessment of Diagnostic Accuracy Studies (QUADAS-2) tool [23], which is composed of 14 questions [24]. The assessment is made up of four primary domains, including patient selection, index detection, reference norm, and flow and timing. Each domain is evaluated according to the risk of bias, and the first three domains are assessed on the basis of applicability. Each item is marked as "high", "low" or "unclear", matches to high risk, low risk, and unclear, respectively.

Statistical analysis. The accuracy indicators for this diagnostic meta-analysis includes the pooled sensitivity (SEN), pooled specificity (SPE), diagnostic odds ratio (DOR), positive likelihood ratio (PLR), negative likelihood ratio (NLR), and their $95 \%$ confidence interval (CI). The analysis of diagnostic accuracy pursuants to a Summary Receiver Operating Characteristic (SROC) curve and the area under curve (AUC) of the SROC. The $I^{2}$ and $Q$ test were performed to assess heterogeneity. A value larger than $50 \%$ for $I^{2}$ or a $P$-value of less than 0.1 for $Q$ test indicates significant heterogeneity, and correspondingly, the random-effect model should be applied. Deeks' funnel plot asymmetry test was used to check the publication bias. Meanwhile, Spearman correlation analysis was used to check the threshold effect. All statistical analyses were performed by using STATA 12.0 .

\section{Results}

Study selection and description. Using the established search strategy, we totally found 440 potentially relevant papers (PubMed: 65; Springer: 276; Web of Science Science: 95; Cochrane Library: 6) (Figure 1). According to the inclusive criteria and exclusive criteria, 8 eligible studies were finally selected $[10,22,25-30]$, as shown in Table 1 . These studies were published between 2000 and 2014. Data were obtained from studies directly or extracted indirectly by calculating the number of people and relevant ratios.

Quality assessment of studies. Based on the QUADAS-2, the outcomes are shown in Table 1. The QUADAS-2 scores of the enrolled studies in this article indicated that the overall quality of these included studies are generally good.

Diagnostic accuracy. The forest plot of SEN, SPE for HA/ HAase assays is shown in Figure 2. The pooled SEN of the included studies of HA test was 0.832 (95\% CI: 0.798, 0.861), the pooled SPE, PLR, NLR, DOR AUC and their 95\% confidence interval were as following: 0.886 (95\% CI: 0.852, 0.913), 7.290 (95\% CI: 5.581, 9.523), 0.190 (95\% CI: 0.157, 0.230), $38.335(95 \%$ CI: $26.250,55.9985)$ and 0.90 (95\% CI: 0.87, 0.92), (shown in Table 2). The diagnostic accuracy of the overall results of HAase test and their 95\% CI were as following: the SEN was 0.834 (95\% CI, 0.756, 0.891), the SPE was 0.860 (95\% 
Table. 1. The characteristics of eligible studies for HA/ HAase test

\begin{tabular}{|c|c|c|c|c|c|c|c|c|c|c|}
\hline No & First Author & Year & Country & QUADAS-2 & Sampling object & Sample size & $\mathrm{TP}$ & FP & $\mathrm{FN}$ & $\mathrm{TN}$ \\
\hline \multirow[t]{3}{*}{1} & Lokeshwar $^{[10]}$ & 2000 & USA & 10 & $\mathrm{HA}$ & 504 & 217 & 24 & 44 & 219 \\
\hline & & & & & HAase & 504 & $\begin{array}{l}159 \\
159\end{array}$ & 50 & 36 & 259 \\
\hline & & & & & HA-HAase & 504 & 240 & 38 & 21 & 205 \\
\hline \multirow[t]{3}{*}{2} & Hautmanm $^{[22]}$ & 2001 & USA & 10 & HA & 46 & 31 & 0 & 3 & 12 \\
\hline & & & & & HAase & 51 & 27 & 4 & 4 & 16 \\
\hline & & & & & HA-HAase & 51 & 30 & 5 & 1 & 15 \\
\hline \multirow[t]{3}{*}{3} & Jamshidian $^{[25]}$ & 2011 & Iran & 12 & HA & 194 & 80 & 10 & 17 & 87 \\
\hline & & & & & HAase & 194 & 60 & 23 & 8 & 103 \\
\hline & & & & & HA-HAase & 194 & 87 & 16 & 10 & 81 \\
\hline 4 & Passerotti ${ }^{[26]}$ & 2011 & Brazil & 10 & HA & 350 & 131 & 37 & 29 & 153 \\
\hline 5 & Eissa $^{[27]}$ & 2012 & Egypt & 12 & HAase & 216 & 89 & 11 & 11 & 105 \\
\hline 6 & Nossier ${ }^{[28]}$ & 2014 & Egypt & 10 & HAase & 66 & 26 & 1 & 14 & 25 \\
\hline 7 & Schroeder ${ }^{[29]}$ & 2004 & Germany & 10 & HA-HAase & 138 & 52 & 15 & 7 & 64 \\
\hline 8 & Hautmanm $^{[30]}$ & 2004 & USA & 12 & HA-HAase & 94 & 25 & 14 & 5 & 50 \\
\hline
\end{tabular}

* ELISA-like assay was used for HA/HAase detection in all the included studies.

* TP: true positive; FP: false positive; FN: false negative; TN: true negative.

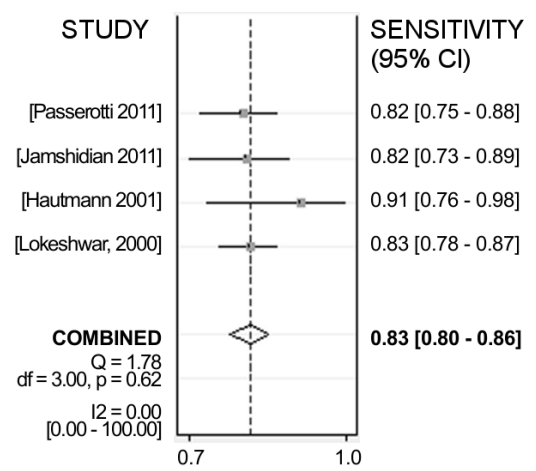

SENSITIVITY

\section{$A(1)$}

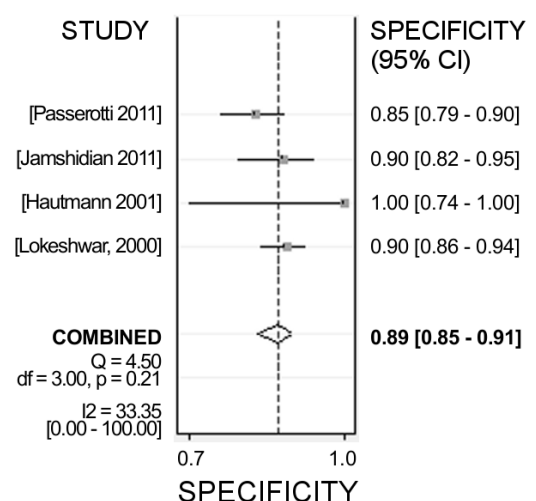

$A(2)$

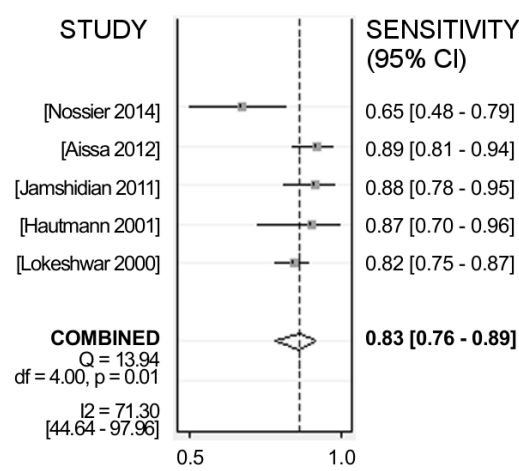

SENSITIVITY

$B(1)$

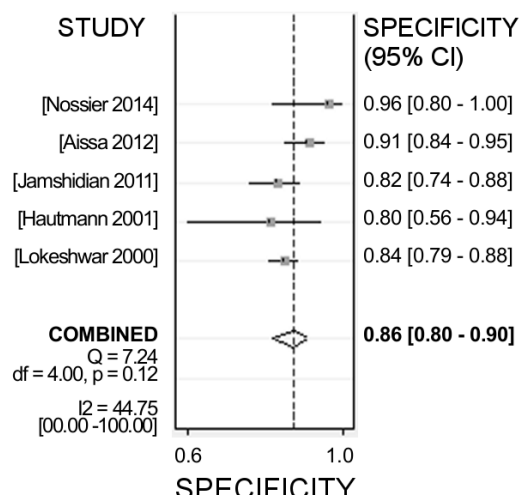

$\mathrm{B}(2)$

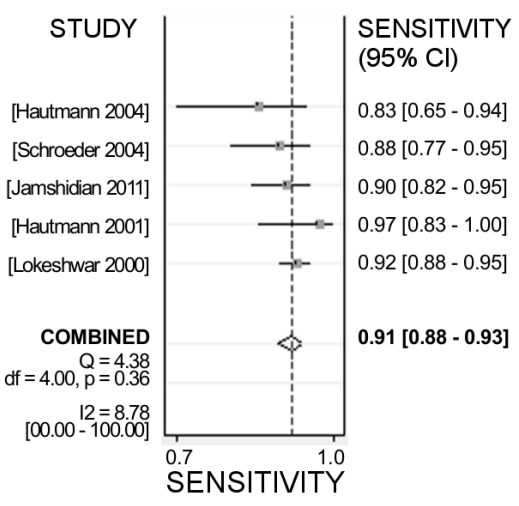

C (1)

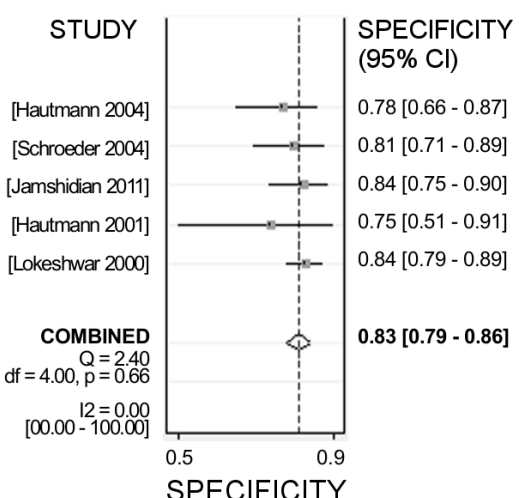

C (2)

Figure 2. Forest plots of $A(1)$ sensitivity for HA test in bladder cancer; $A(2)$ specificity for HA test in bladder cancer; B(1) sensitivity for HAase test in bladder cancer; $\mathrm{B}(2)$ specificity for HAase test in bladder cancer; $\mathrm{C}(1)$ sensitivity for HA-HAase test in bladder cancer; C(2) specificity for HA-HAase test in bladder cancer. 
Table 2. Sensitivity, specificity and accuracy calculations of the included HA, HAase and HA-HAase tests

\begin{tabular}{lccc}
\hline Category & HA test & HAase test & HA-HAase test \\
\hline Sensitivity & $0.832(0.798,0.861)$ & $0.834(0.756,0.891)$ & $0.908(0.879,0.931)$ \\
Specificity & $0.886(0.852,0.913)$ & $0.860(0.801,0.904)$ & $0.825(0.789,0.856)$ \\
AUC & $0.90(0.87,0.92)$ & $0.91(0.88,0.93)$ & $0.94(0.91-0.95)$ \\
\hline
\end{tabular}

CI: 0.801, 0.904), the PLR was 5.963 (95\% CI: 4.215, 8.438), the NLR was 0.193 (95\% CI: $0.131,0.285)$, and the DOR was 30.869 (95\% CI: 18.071, 52.730). The AUC of HAase tests was 0.91 (95\% CI: $0.88,0.93)$, indicating a relatively high diagnostic accuracy. The SROC curves for the included studies were shown in Figure 3. In addition, we also analyzed the pooled parameter of HA-HAase test, the AUC of HA-HAase was 0.94 (95\% CI: 0.91, 0.95), showed a relatively higher diagnostic value than HA test and HAase test.

Threshold effect and heterogeneity analysis. During the research process, different studies could lead to different sensitivity and specificity, resulting in threshold effect and diagnostic odds ratios (DOR). If a threshold effect exists, the worker receiver operating characteristic (ROC) plane scatter distribution is in a typical "shoulder arm-shaped" style, and the sensitivity would show a negative correlation to the specificity. In our analysis, the HA/HAase of SROC curve did not show this typical style (Figure 3), suggesting that there was no threshold effect.

In this paper, the diagnostic odds ratio was also used to explore the heterogeneity caused by non-threshold effect. For the HAase test, the results showed that the $I^{2}$ is $51.7 \%$, indicating high heterogeneity among enrolled studies. To evaluate potential sources of between-study heterogeneity, we performed a further analysis. According to the original information, we studied tumor data by different grades (G1, G2 and G3). But unfortunately, limited by the samples in our meta-analysis, we got the tumor grades only from 3 articles (Table 3 ). And we found that the sensitivity of HAase for the diagnosis of G1 was much lower than G2 and G3, with sensitivity ranging from $81.2 \%$ to $100 \%$.

Publication bias. Deeks'funnel plot asymmetry test was used to evaluate publication bias. The $P$-value of the HA test, HAase test and HA-HAase test were $0.343,0.563,0.414$, respectively. The results suggested that no significant publication bias existed among the included HA/HAase studies.

Clinical utility of index test. Fagan's nomogram was shown for figuring up post-test probabilities (PTPs) (Figure 4). The Fagan's nomogram for the included HA tests showed that when

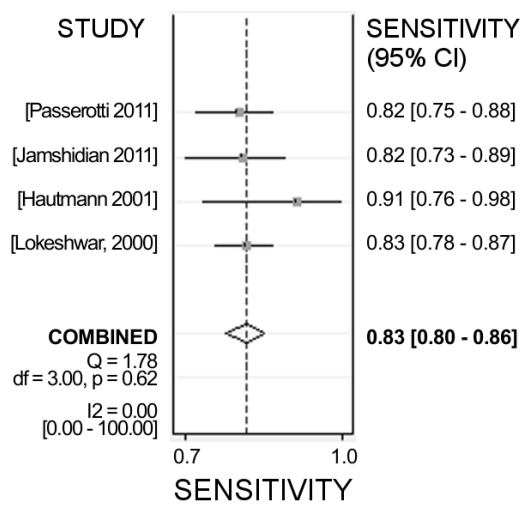

$A(1)$

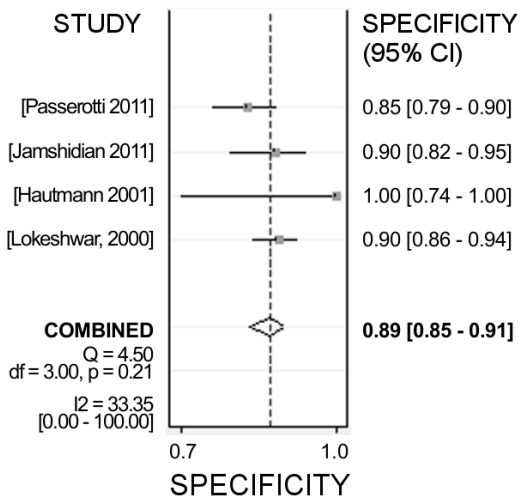

$A(2)$

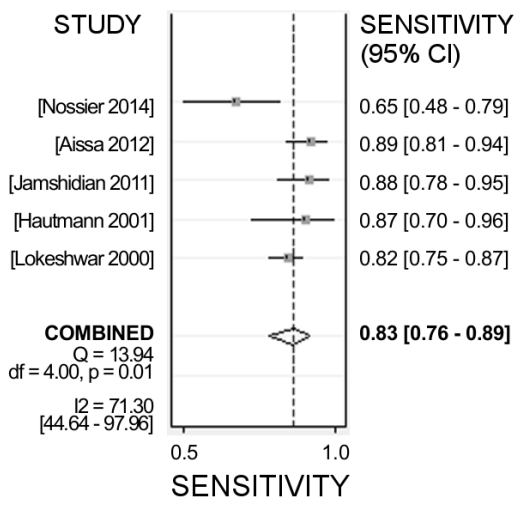

$B(1)$

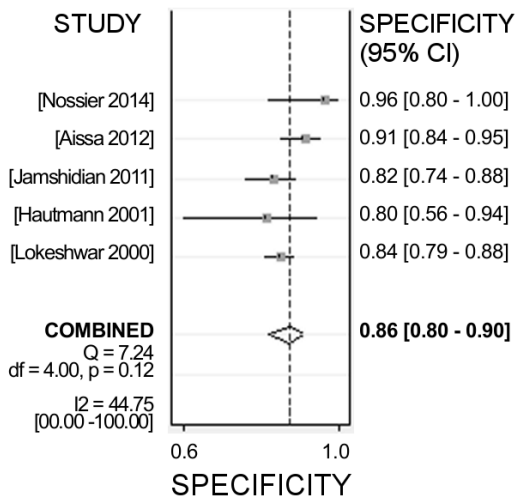

B (2)

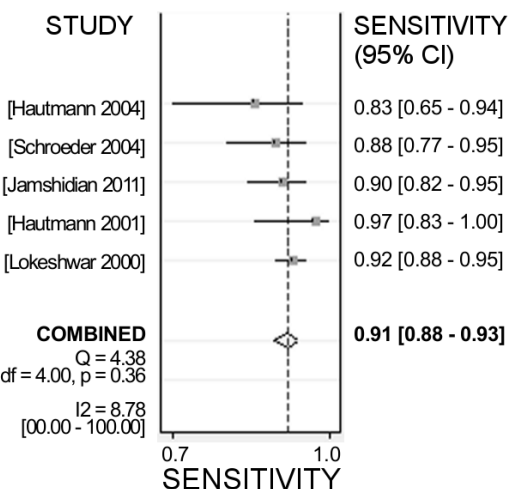

C (1)

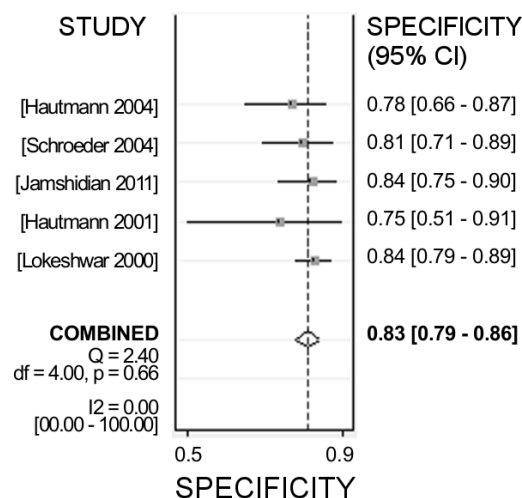

C (2)

Figure 3. Summary ROC curve of HA (A), HAase (B), HA-HAase (C) test for pooled sensitivity and pooled specificity. 
Table 3. The information of tumor grades for the included HAase tests.

\begin{tabular}{lccccc}
\hline Author & year & Collecting time & Patients age (years) & Grade 1 & Grade 2 \\
\hline Lokeshwar & 2000 & $1995.1-1998.9$ & $34-90$ & $15 / 66$ & $38 / 46$ \\
Eissa & 2012 & NG & $37-78$ & $65 / 76$ \\
Jamshidian & 2011 & $2007.7-2008.3$ & $34-91$ & $7 / 29$ & $24 / 24$ \\
\hline
\end{tabular}

NG: not given

$20 \%$ was used as the pre-test probability, the post-test probability would raise to $65 \%$ with a positive likelihood ratio of 7 , and the probability would decrease to $5 \%$, and the negative likelihood ratio is 0.19 . For the HAase test, from the Fagan's nomogram, we found that when $20 \%$ was used as the pre-test probability, the post-test probability would raise to $60 \%$ with a positive likelihood ratio of 6 , and the probability would decrease to $5 \%$, and the negative likelihood ratio is 0.19 . As for HA-HAase test, the Fagan's nomogram showed that when $20 \%$ was used as the pre-test probability, the post-test probability would rise to $56 \%$ with a positive likelihood ratio of 5 , and the probability would decrease to $3 \%$, and the negative likelihood ratio is 0.11 .

\section{Discussion}

In the clinical practice, cystoscopy and urinary cytology are the most common methods for BC diagnosis [31] Cystoscopy is the gold standard and urine cytology is the widely-used method. But the two methods also have shortcomings [32], they are costly, unpleasant, time consuming and trained personnel requirement [33]. At present, it is still a hot point to find biomarkers for the diagnosis of bladder cancer [34, 35]. HA is known to promote tumor metastasis and help avoid immune surveillance by forming a protective coat around the tumor cells [36]. HAase, an endoglycosidase, degrades HA into small fragments that promote angiogenesis. Although HA/HAase has already been widely regarded as a biomarker [37-39], the small sample sizes and the lower statistical power of those single experiment limit their application. In this study, 8 papers with 1645 cases and controls were enrolled, the value of HA/ HAase in bladder cancer diagnose was confirmed.

After a careful and serious data collection and analysis by software, we found that the pooled SEN of the included HA tests was 0.832 , the pooled SPE 0.886 . Both the sensitivity and specificity are greater than 0.80 , indicating a gooddiagnostic accuracy. As for the HAase test, the pooled SEN was 0.834 , the pooled SPE was 0.860 , also showing a high potential diagnostic value of HAase as a noninvasive test, what's more, the pooled DOR was 30.869, indicating that the overall accuracy of HAase test for bladder cancer diagnosis is credible. As for SROC curve, the area under the summary ROC cure (AUC) of HA test was 0.90 and the AUC of HAase was 0.91. SROC is

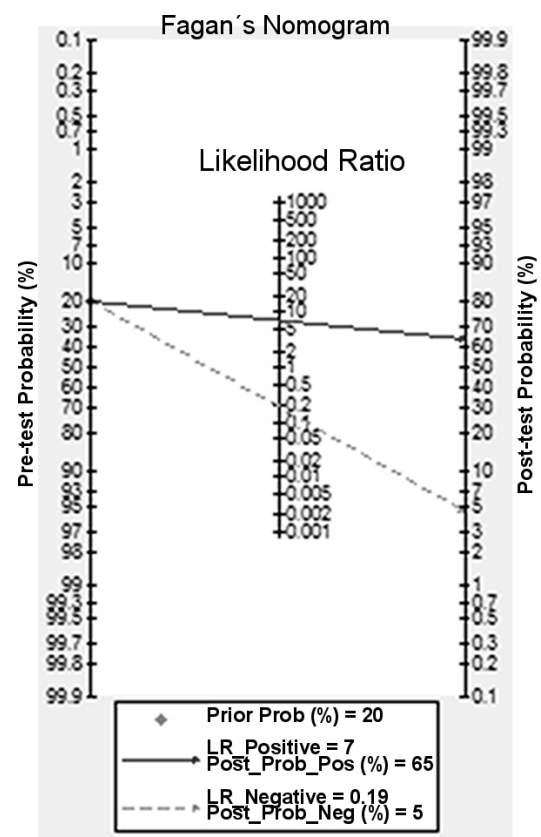

A

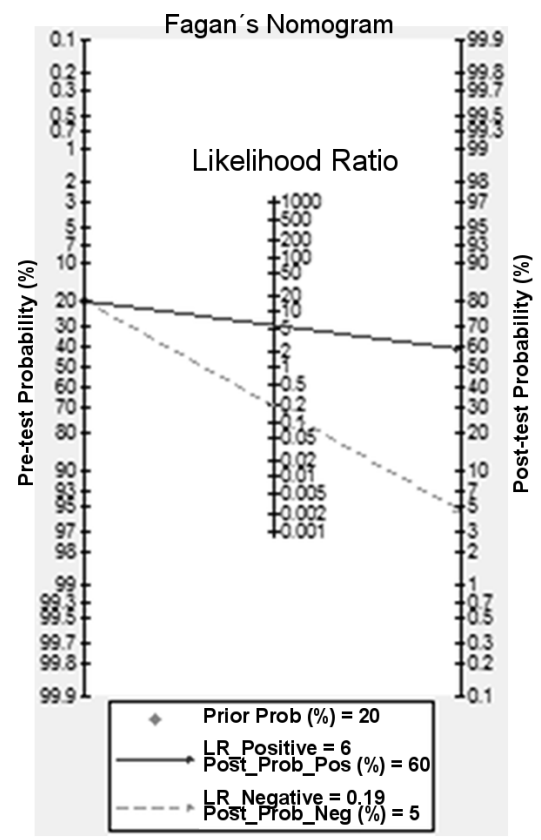

B

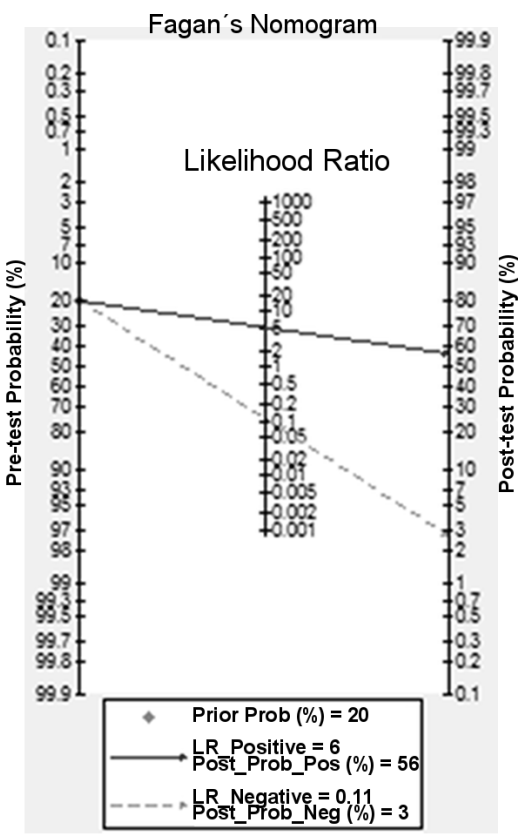

C

Figure 4 Fagan's nomogram: A straight line was used to contact the pretest probability of bladder tumor with HA, HAase, HA-HAase, by crossing the likelihood ratio line at a point that describes the results acquired. 
normally used to sum up overall test performance and AUC serves as a measurement indicator [40]. In this article, the results showed that both HA test and HAase test had a good accuracy in diagnosing and testing $\mathrm{BC}$ with an $\mathrm{AUC}$ greater or equal to 0.90. In addition, the SROC curve, DOR and AUC values are not the only viable strategies for clinical diagnosis, the likelihood ratios (LR), including positive likelihood (PLR) and negative likelihood (NLR), also play a similar role in the evaluation of diagnostic accuracy [34]. For the HAase test, the pooled PLR of 5.963suggested that patients with bladder cancer had a 5.963fold higher chance to have a positive result compared with controls. A pooled NLR of 0.193 meant that the probability of the individuals with bladder cancer was $19.3 \%$ when the HAase test was negative. All the results indicated that as a biomarker, HAase would be an accurate method for $\mathrm{BC}$ diagnosis. In this article, we compared the diagnostic value of HA test and HAase test with HA-HAase test, and found that the sensitivity of the combined test was 0.908 , the pooled specificity was 0.825 and the AUC value was slightly increases to 0.94 , indicating that the combination of HA and HAase had a better potential to be used as a biomarker for bladder cancer detection.

As mentioned above, different studies about the HA/HAase diagnostic value showed different results, and that was also the reason why we conducted this meta-analysis. From our study, the pooled sensitivity of HA test, HAase test and HA-HAase test were all greater than 0.80 , even reached up to 0.904 for the combined test. The pooled specificity of the three methods were also greater than 0.80 . These results indicated that HA/ HAase had high sensitivity and specificity for early bladder cancer detection, which could make up the low sensitivity and specificity of cytology and cystoscopy. At present, several new biomarkers such as TERT and FGFR3 mutations, microRNA, telomerase, CD44 variants, cytokeratin 20 and others have shown their potential to be used as early diagnostic methods for detecting bladder cancer [41-44]. However, none of these markers are either as sensitive or as specific as the HA/HAase test. What's more, in this study, the AUC of the HA/HAase tests are all greater or equal to 0.90 , strongly suggested that $\mathrm{HA} / \mathrm{HAase}$ could be used as biomarkers for the diagnosis of bladder cancer.

Heterogeneity is a latent problem for the results of metaanalysis $[45,46]$, as non-homogeneous data are easy to cause misleading results. Among the different kinds of bias, the threshold effect must be considered firstly, so we used Spearman correlation coefficient to test the threshold effect, and its value was $0.029(P=0.957)$, suggesting that there was no heterogeneity from threshold effects. Previous studies showed that the HA/HAase levels gradually raised as the tumor grades increased. Lokeshwar and colleagues reported that the mean urinary HAase levels were 2.6- 7-fold higher in patients with G2 and G3 bladder cancer as compared with the levels in patients with G1 bladder cancer [10]. In this meta-analysis, the data showed that the $I^{2}$ for sensitivity of HAase test was $70.83 \%$ and the $I^{2}$ for specificity was $55.35 \%$. As we are clear that sensitivity might be influenced by different tumor grades, then we performed a further analysis to determine the sensitiv- ity of the HAase for detecting different grade bladder cancers. But, unfortunately, limited by the samples in our meta-analysis, we got the information of tumor grades from only 3 articles, and the data was not enough to conduct a subgroup analysis. Through a simple calculation, we found that the sensitivity of HAase in bladder cancer with G1 is much lower than those with G2/G3. And the sensitivity of HAase in bladder cancer patients with G2 or G3 tumors ranges from $81.2 \%$ to $100 \%$, indicating that HAase has a good diagnostic value for $\mathrm{G} 2$ and G3 bladder cancer but not for G1 bladder cancer.

However, this meta-analysis still has several limitations. Firstly, only those papers written in English were included, relevant articles using other languages had not be enrolled in. Secondly, all records we searched are published articles, as a result, unpublished data were not included, some useful information may be lost with much possible. Although, Deeks'funnel plot asymmetry test showed that no significant publication bias among the included studies, however, the bias caused by those unpublished data should not be completely ignored. Thirdly, despite of the strict inclusive criteria, significant heterogeneity was still detected among the enrolled studies. To explore the source of the heterogeneity, we should have performed a subgroup analysis, but we could not effectively implemented because of the limited data. What's more, in clinical practice, bladder cancer is often treated by transurethral resection (TUR) or bacille Calmette-Gue'rin therapy (BCG) which could lead to an increase of urinary tract infection [47-50], in addition, HA is known to play an important role in the tissue response to injury and inflammation [51], and Bollyky PL also reported that injury and inflammation could enhance HA production [52]. The above-mentioned results suggested TUR or BCG might have effects on HA level. To figure out the effects of TUR or BCG, we analyzed the included papers, Passerotti [26], Nossier [28] and Schroeder [29] clearly pointed out that the samples they detected were all collected prior to treatment or surgery; but all of the studies conducted by Hautmanm [22], Jamshidian [25], Eissa [27] and Hautmanm [30] did not clarify whether the sample were collected prior to treatment or not; only in Lokeshwar's study ${ }^{[10]}$, they reported that among all the 261 bladder cancer patients, $72 \%$ were new cases and $28 \%$ were recurrences, and the patients with recurrence had been treated previously either by transurethral resection of the bladder (TUR) alone or followed by intra vesicle therapy (BCG or mitomycin C), and they pointed out that these treatments did not appear to affect the results. To further rule out the confounding, we need to develop a study to confirm whether TUR/BCG influence HA/ HAase level or not. But we could not get an exact conclusion from current papers. In the future, researchers should collect samples from bladder cancer patients treated by TUR/BCG and matched controls, and then detect their HA/HAase level respectively, and finally, conduct a laboratory validation.

Acknowledgments: This study was supported by Technology Project of the Department of Health of Jilin Province (Grant No. 20165044). 


\section{References}

[1] SARTINi D, MUZZONIGRO G, MilANESE G, POZZI V, VICI A et al. Upregulation of tissue and urinary nicotinamide N-methyltransferase in bladder cancer: Potential for the development of a urine-based diagnostic test. Cell Biochem Biophys 2013; 65: 473-483. https://doi.org/10.1007/s12013-012-9451-1

[2] GLOBAL BURDEN OF DISEASE CANCER COLLABORATION, FITZMAURICE C, DICKER D, PAIN A, HAMAVID $\mathrm{H}$ et al.The global Burden of Cancer 2013. JAMA Oncol 2015; 1: 505-527. https://doi.org/10.1001/jamaoncol.2015.0735

[3] JEMAL A, BRAY F, CENCER M M, FERLAY J, WARD E et al. Globle cancer statistics. CA Cancer J Clin 2011; 61: 69-90. https://doi.org/10.3322/caac.20107

[4] SANNA E, SAMAR K, RANDA AL, EL-KHOULY IM, GHAFFER TM et al. Detection of Bladder Carcinoma by Combined Testing of Urine For Hyaluronidase and Cytokeratin 20 RNAs. Cancer 2005; 103: 1356-1362. https://doi.org/10.1002/cncr.20902

[5] BABJUK M, BURGER M, ZIGEUNER R, SHARIAT SF, VAN RHIJN BW et al. EAU guidelines on non-muscle-invasive urothelial carcinoma of the bladder: update 2013. Eur Urol 2013; 64: 639-653 https://doi.org/10.1016/i.eururo.2013.06.003

[6] SRIVASTAVA AK, SINGH PK, SRIVASTAVA K, SINGH D, DALELA D et al. Diagnostic role of survivin in urinary bladder cancer. Asian Pac J Cancer Prev 2013; 14: 81-85. https:// doi.org/10.7314/APJCP.2013.14.1.81

[7] Guo A, Wang X, Gao L, Shi J, Sun C et al. Bladder tumour antigen (BTA stat) test compared to the urine cytology in the diagnosis of bladder cancer: A meta-analysis. Can Urol Assoc J 2014; 8: e347-352. https://doi.org/10.5489/cuaj.1668

[8] SCHMITZ-DRAGER BJ, TODENHÖFER T, VAN RHIJN $\mathrm{B}, \mathrm{PESCH} \mathrm{B}, \mathrm{HUDSON}$ MA et al. Considerations on the use of urine markers in the management of patients with low-/intermediate-risk non-muscle invasive bladder cancer. Urol Oncol 2014; 32: 1061-1068. https://doi.org/10.1016/j. urolonc.2013.10.010

[9] CHENG D, HAN W, YANG K, SONG Y, JIANG $M$ et al. One-step facile synthesis of hyaluronic acid functionalized fluorescent gold nanoprobes sensitive to hyaluronidase in urine specimen from bladder cancer patients. Talanta 2014; 130: 408-414. https://doi.org/10.1016/j.talanta.2014.07.005

[10] LOKESHWAR VB, OBEK C, PHAM HT, WEI D, YOUNG MJ et al. Urinary hyaluronic acid and hyaluronidase: markers for bladder cancer detection and evaluation of grade. J Urol 2000; 163: 348-356. https://doi.org/10.1016/S0022-5347(05)68050-0

[11] STERN M, LONGAKER MT, ADZICK NS, HARRISON MR, STERN R. Hyaluronidase levels in urine from Wilms tumor patients. J Natl Cancer Inst 1991; 83: 1569-1574. https://doi. org/10.1093/jnci/83.21.1569

[12] LOKESHWAR VB, LOKESHWAR BL, PHAM HT, BLOCK NL. Association of elevated levels of hyaluronidase, a matrixdegrading enzyme, with prostate cancer progression. Cancer Res 1995; 56: 651-657.

[13] KOUVIDI K, BERDIAKI A, NIKITOVIC D, KATONIS P, AFRATIS $\mathrm{N}$ et al. Role of receptor for hyaluronic acid-mediated motility (RHAMM) in low molecular weight hyaluronan (LMWHA)-mediated fibrosarcoma cell adhesion. J Biol
Chem 2011; 286: 38509-38520. https://doi.org/10.1074/jbc. $\underline{\mathrm{M} 111.275875}$

[14] KOWITSCH A, YANG Y, MA N, KUNTSCHE J, MADER $\mathrm{K}$ et al. Bioactivity of immobilized hyaluronic acid derivatives regarding protein adsorption and cell adhesion. Biotechnol Appl Biochem 2011; 58: 376-389. https://doi.org/10.1002/bab.41

[15] SVENSSON HOLM AC, BENGTSSON T, GRENEGARD M, LINDSTROM EG. Hyaluronic acid influence on plateletinduced airway smooth muscle cell proliferation. Exp Cell Res 2012; 318: 632-640. https://doi.org/10.1016/j.yexcr.2011.12.011

[16] CHAO D, FREEDLAND SJ, PANTUCK AJ, ZISMAN A, BELLDEGRUN AS. Bladder cancer 2000: molecular markers for the diagnosis of transitional cell carcinoma. Rev Urol 2001; 3: 85-93.

[17] SCHMAUS A, KLUSMEIER S, ROTHLEY M, DIMMLER A, SIPOS B et al. Accumulation of small hyaluronan oligosaccharides in tumour interstitial fluid correlates with lymphatic invasion and lymph node metastasis. Br J Cancer 2014; 111: 559-567. https://doi.org/10.1038/bjc.2014.332

[18] LOKESHWAR VB, CERWINKA WH, ISOYAMA T, LOKESHWAR BL. HYAL1 hyaluronidase in prostate cancer: a tumor promoter and suppressor. Cancer Res 2005; 65: 7782-7789. https://doi.org/10.1158/0008-5472.CAN-05-1022

[19] LOKESHWAR VB, CERWINKA WH, LOKESHWAR BL. HYAL1 hyaluronidase: a molecular determinant of bladder tumor growth and invasion. Cancer Res 2005; 65: 2243-2250. https://doi.org/10.1158/0008-5472.CAN-04-2805

[20] SIMPSON MA, LOKESHWAR VB. Hyaluronan and hyaluronidase in genitourinary tumors. Front Biosci 2008; 13: 5664-5680.

[21] LOKESHWAR VB, OBEK C, SOLOWAY MS, BLOCK NL. Tumor-associated hyaluronic acid: a new sensitive and specifc urine marker for bladder cancer. Cancer Res 1997; 57: 773-777.

[22] HAUTMANN SH, LOKESHWAR VB, SCHROEDER GL, CIVANTOS F, DUNCAN RC et al. Elevated tissue expression of hyaluronic acid and hyaluronidase validates the HA-HAase urine test for bladder cancer. J Urol 2001; 165: 2068-2074. https://doi.org/10.1016/S0022-5347(05)66296-9

[23] WHITING PF, RUTJES AW, WESTWOOD ME, MALLETT S, DEEKS JJ et al. QUADAS-2: A Revised Tool for the Quality Assessment of Diagnostic Accuracy Studies. Ann Intern Med 2011; 155: 529-536. https://doi.org/10.7326/0003-4819-1558-201110180-00009

[24] WHITING P, RUTJES AW, REITSMA JB, BOSSUYT PM, KLEIJNEN J. The development of QUADAS: a tool for the quality assessment of studies of diagnostic accuracy included in systematic reviews. BMC Med Res Methodol 2003; 3: 25. https://doi.org/10.1186/1471-2288-3-25

[25] JAMSHIDIAN H, HASHEMI M, NOWROOZI MR, AYATI $\mathrm{M}, \mathrm{BONYADI} \mathrm{M}$ et al. Sensitivity and specificity of urinary hyaluronic acid and hyaluronidase in detection of bladder transitional cell carcinoma. Urol J 2011; 11: 1232-1237.

[26] PASSEROTTI CC, SROUGI M, BOMFIM AC, MARTINS JR, LEITE KR et al. Testing for urinary hyaluronate improves detection and grading of transitional cell carcinoma. Urol Oncol 2011; 29: 710-715. https://doi.org/10.1016/j.urolonc.2009.10.006

[27] EISSA S, ZOHNY SF, SHEHATA HH, HEGAZY MG, SALEM $\mathrm{AM}$ et al. Urinary retinoic acid receptor- $\beta 2$ gene promoter methylation and hyaluronidase activity as noninvasive tests for 
diagnosis of bladder cancer. Clin Biochem 2012; 45: 402-407. https://doi.org/10.1016/j.clinbiochem.2012.01.010

[28] NOSSIER AI, EISSA S, ISMAIL MF, HAMDY MA, AZZAZY HM. Direct detection of hyaluronidase in urine using cationic gold nanoparticles: a potential diagnostic test for bladder cancer. Biosens Bioelection 2014; 54: 7-14. https:// doi.org/10.1016/j.bios.2013.10.024

[29] SCHROEDER GL, LORENZO-GOMEZ MF, HAUTMANN SH, FRIEDRICH MG, EKICI S et al. A side by side comparison of cytology and biomarkers for bladder cancer detection. J Urol 2004; 172: 1123-1126. https://doi.org/10.1097/01. ju.0000134347.14643.ab

[30] HAUTMANN S, TOMA M, LORENZO GOMEZ MF, FRIEDRICH MG, JAEKEL T et al. Immunocyt and the HA-HAase urine tests for the detection of bladder cancer: a side-byside comparison. Eur Urol 2004; 46: 466-471. https://doi. org/10.1016/j.eururo.2004.06.006

[31] PARK JC, CITRIN DE, AGARWAL PK, APOLO AB. Multimodal management of muscle invasive bladder cancer. Curr Probl Cancer 2014; 38:80-108. https://doi.org/10.1016/j. currproblcancer.2014.06.001

[32] FATHIA ES, MAHMOUD ES, ZEINAB H, KHALED H. The biochemical value of urinary metalloproteinases 3 and 9 in diagnosis and prognosis of bladder cancer in Egypt. J Biomed Sci 2014; 21: 72. https://doi.org/10.1186/s12929-014-0072-4

[33] SOUKUP V, KALOUSOVA M, CAPOUN O, SOBOTKA R, BREYL $Z$ et al. Panel of Urinary Diagnostic Markers for Non-Invasive Detection of Primary and Recurrent Urothelial Urinary Bladder Carcinoma. Urol Int 2015; 95: 56-64. https:// doi.org/10.1159/000368166

[34] MILOWICH D, LE MERCIER M, DE NEVE N, SANDRAS F, ROUMEGUERE T et al. Diagnostic value of the UCA1 test for bladder cancer detection: a clinical study. Springerplus 2015; 4: 349. https://doi.org/10.1186/s40064-015-1092-6

[35] ARDELL P, GRUNEMAY N, STREHL A, JILG C, MIERNIK A. LASP-1, a novel urinary marker for detection of bladder cancer. Urol Oncol 2013; 31: 1591-1598. https://doi.org/10.1016/j. urolonc.2012.02.002

[36] Knudson W. Tumor-associated hyaluronan: providing an extracellular matrix that facilitates invasion. Am J Pathol 1996; 148: 1721-1726.

[37] SAAD A, HANBURY DC, MCNICHOLAS TA, BOUSTEAD $\mathrm{GB}, \mathrm{MORGAN} S$ et al. A study comparing various noninvasive methods of detecting bladder cancer in urine. BJU Int 2002; 89: 369-373. https://doi.org/10.1046/j.1464-4096.2001.01699.X

[38] CHENG Y, DENG X, YANG X, LI P, ZHANG X et al. Urine microRNAs as biomarkers for bladder cancer: a diagnostic meta-analysis. Onco Targets Ther 2015; 8: 2089-2096.

[39] CHIB R, RAUT S, FUDALA R, CHANG A, MUMMERT M et al. FRET based ratio-metric sensing of hyaluronidase in synthetic urine as a biomarker for bladder and prostate cancer. Curr Pham Biotechnol 2013; 14: 470-474. https://doi.org/10.2 $\underline{174 / 13892010113149990222}$

[40] JONES CM, ATHANASIOU T. Summary receiver operating characteristic curve analysis techniques in the evaluation of diagnostic tests. Ann Thorac Surq 2005; 79: 16-20. https:// doi.org/10.1016/j.athoracsur.2004.09.040
[41] CRITELLI R, FASANELLI F, ODERDA M, POLIDORO S, ASSUMMA MB et al. Detection of multiple mutations in urinary exfoliated cells from male bladder cancer patients at diagnosis and during follow-up. Oncotarget 2016; 7: 67435-67448. https://doi.org/10.18632/oncotarget.11883

[42] WANG J, ZHANG X, WANG L, DONG Z, DU L et al. Downregulation of urinary cell-free microRNA-214 as a diagnostic and prognostic biomarker in bladder cancer. J Surg Oncol 2015; 111: 992-999. https://doi.org/10.1002/jso.23937

[43] CAVALLO D, CASADIO V, BRAVACCINI S, IAVICOLI S, PIRA E et al. Assessment of DNA damage and telomerase activity in exfoliated urinary cells as sensitive and noninvasive biomarkers for early diagnosis of bladder cancer in ex-workers of a rubber tyres industry. Biomed Res Int 2014; 2014: 370907. https://doi.org/10.1155/2014/370907

[44] EISSA S, ZOHNY SF, SWELLAM M, MAHMOUD MH, EL-ZAYAT TM et al. Comparison of CD44 and cytokeratin 20 mRNA in voided urine samples as diagnostic tools for bladder cancer. Clin Biochem 2008; 41: 1335-1341. https:// doi.org/10.1016/j.clinbiochem.2008.08.085

[45] YANG X, HUANG H, ZENG Z, ZHAO L, HU P et al. Diagnostic value of bladder tumor fibronectin in patients with bladder tumor: A systematic review with meta-analysis. Clinical Biochemistry 2013; 46: 1377-1382. https://doi.org/10.1016/j. clinbiochem.2013.05.064

[46] MORENO SG, SUTTON AJ, THOMPSON JR, ADES AE, ABRAMS KR et al. A generalized weighting regressionderived meta-analysis estimator robust to small-study effects and heterogeneity. Stat Med 2012; 31: 1407-1417. https://doi. org/10.1002/sim. 4488

[47] GREGG JR, MCCORMICK B, WANG L, COHEN P, SUN D et al. Short term complications from transurethral resection of bladder tumor. Can J Urol 2016; 23: 8198-8203.

[48] MATULEWICZRS, SHARMA V,MCGUIREBB, OBERLINDT, PERRY KT et al. The effect of surgical duration of transurethral resection of bladder tumors on postoperative complications: An analysis of ACS NSQIP data. Urol Oncol 2015; 33: 338.e19-24. https://doi.org/10.1016/j.urolonc.2015.05.011

[49] STRÖCK V, DOTEVALL L, SANDBERG T, GUSTAFSSON CK, HOLMÄNG S. Late bacille Calmette-Guérin infection with a large focal urinary bladder ulceration as a complication of bladder cancer treatment. BJU Int 2011; 107: 1592-1597. https://doi.org/10.1111/j.1464-410X.2010.09923.x

[50] PEREZ-JACOISTE ASIN MA, FERNANDEZ-RUIZ M, LOPEZ-MEDRANO F, LUMBRERAS C, TEJIDO A et al. Bacillus Calmette-Guérin (BCG) infection following intravesical BCG administration as adjunctive therapy for bladder cancer: incidence, risk factors, and outcome in a single-institution series and review of the literature. Medicine (Baltimore) 2014; 93: 236-254. https://doi.org/10.1097/MD.0000000000000119

[51] JIANG D, LIANG J, NOBLE PW. Hyaluronan in tissue injury and repair. Annu Rev Cell Dev Biol 2007; 23: 435-461. https:// doi.org/10.1146/annurev.cellbio.23.090506.123337

[52] BOLLYKY PL, BOGDANI M, BOLLYKY JB, HULL RL, WIGHT TN. The role of hyaluronan and the extracellular matrix in islet inflammation and immune regulation. Curr Diab Rep 2012; 12: 471-480. https://doi.org/10.1007/s11892-012-0297-0 